\title{
Análise e identificação de nematoides fitófagos em área irrigada por pivô central
}

\author{
Analysis and identification of phytophagous nematodes in an irrigated area by central pivot \\ Análisis e identificación de nematodos fitófagos en zona de regadío mediante pivote central
}

Recebido: 19/04/2021 | Revisado: 26/04/2021 | Aceito: 02/05/2021 | Publicado: 16/05/2021

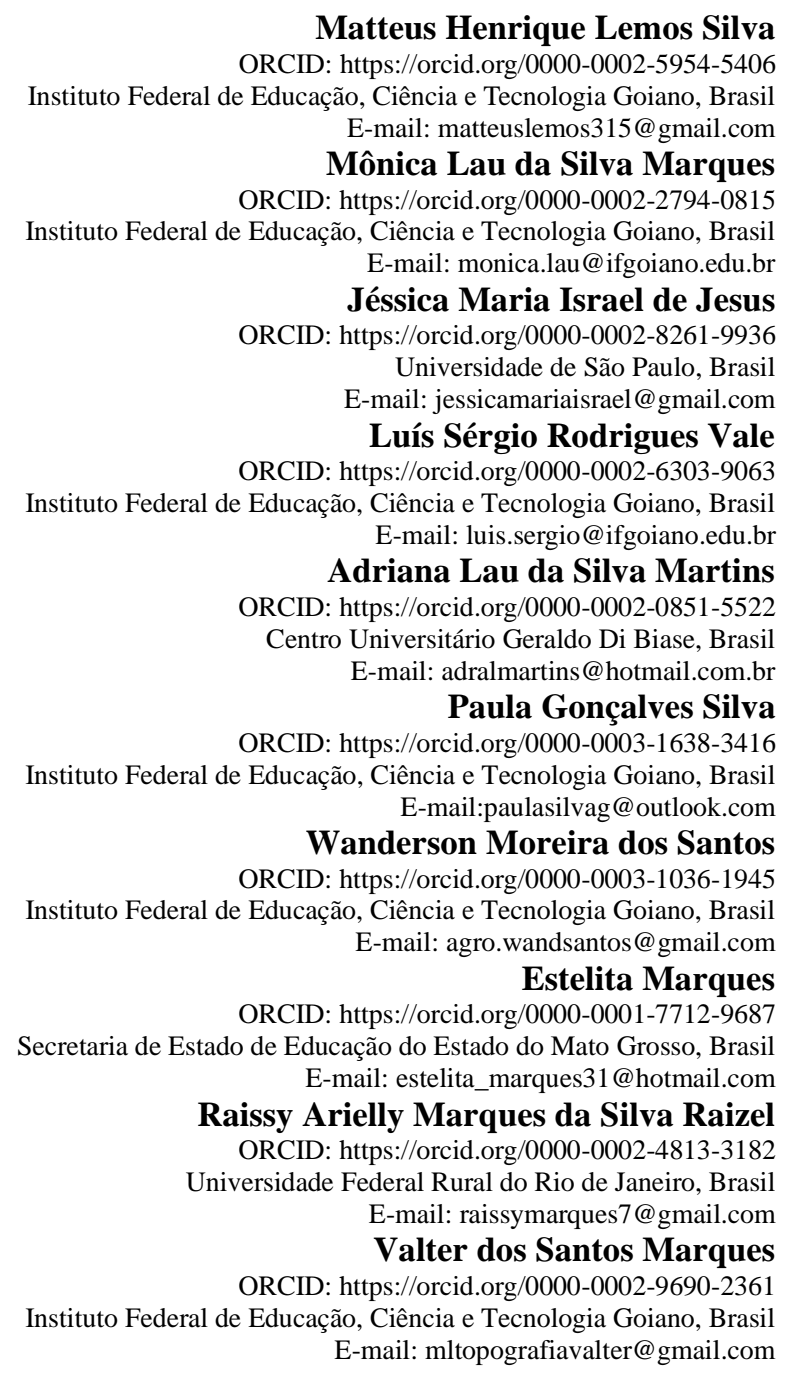

\section{Resumo}

Os nematoides podem trazer efeitos variados para a agricultura. Algumas espécies podem acarretar danos à produção, e outras espécies de vida livre podem ser benéficas para os patossistemas. As espécies de fitófagos dificultam a absorção de água e consequentemente de nutrientes, provocando danos às raízes e subsequente queda da produção. Conhecer o solo, não só sua composição química e física, mas também seu macro e microbiota são fundamentais para a produtividade das culturas. Diante disso, este trabalho teve como objetivo identificar as populações de nematoides e suas características na área de irrigação do pivô central, no Instituto Federal Goiano Campus Ceres-GO. A amostragem, a identificação, a quantificação e caracterização foram feitas nos períodos de cultivo da área, sendo respeitadas as fases fenológicas das mesmas. Após a coleta, foram analisadas as características físicas e químicas do solo, que apresentou-se extremamente argiloso, e com boa fertilidade. Já nas análises nematológicas, não foram detectadas a presença de nematoides nas amostras coletadas na área de pivô central.

Palavras-chave: Agricultura; Fitonematoides; Irrigação; Pivô.

\section{Abstract}

Nematodes can have varied effects on agriculture. Some species can cause damage to production, and other freeliving species can be beneficial to pathosystems. Phytophagous species hinder the absorption of water and, 
consequently, nutrients, causing damage to the roots and subsequent fall in production. Knowing the soil, not only its chemical and physical composition, but also its macro and microbiota, are fundamental for crop productivity. Therefore, this work aimed to identify the nematode populations and their characteristics in the central pivot irrigation area, at the Instituto Federal Goiano Campus Ceres-GO. Sampling, identification, quantification and characterization were done during the cultivation periods of the area, with respect to their phenological phases. After the collection, the physical and chemical characteristics of the soil were analyzed, which showed to be extremely clayey, and with good fertility. In nematological analyzes, the presence of nematodes was not detected in the samples collected in the central pivot area.

Keywords: Agriculture; Phytonematodes; Irrigation; Pivot.

\section{Resumen}

Los nematodos pueden tener diversos efectos en la agricultura. Algunas especies pueden dañar la producción y otras especies de vida libre pueden ser beneficiosas para los patosistemas. Las especies fitófagas dificultan la absorción de agua y, en consecuencia, de nutrientes, provocando daños en las raíces y posterior caída de la producción. Conocer el suelo, no solo su composición química y física, sino también su macro y microbiota, son fundamentales para la productividad de los cultivos. Por lo tanto, este estudio tuvo como objetivo identificar las poblaciones de nematodos y sus características en el área de riego de pivote central, en el Instituto Federal Goiano Campus Ceres-GO. Se realizaron muestreos, identificación, cuantificación y caracterización durante los períodos de cultivo de la zona, con respecto a sus fases fenológicas. Luego de la recolección, se analizaron las características físicas y químicas del suelo, el cual mostró ser extremadamente arcilloso y con buena fertilidad. En los análisis nematológicos, no se detectó la presencia de nematodos en las muestras recolectadas en el área del pivote central.

Palabras clave: Agricultura; Fitonematodos; Irrigación; Pivote.

\section{Introdução}

Os nematoides podem trazer efeitos variados para a agricultura. Algumas espécies podem acarretar danos, já outras espécies de vida livre podem ser benéficos para os patossistemas. As espécies de fitófagos dificultam a absorção de água e consequentemente de nutrientes, provocando danos às raízes pela formação de nódulos ou necrose (Hussey \& Williamson, 1998). No solo, a sua distribuição se dá por reboleiras, devido a sua baixa capacidade de disseminação por movimentação.

Nesse sentido, as populações de nematoides fitófagos tendem a serem maiores próximas às plantas hospedeiras que servem como alimento. Como resultados do aumento das populações nessas áreas observa-se a presença de reboleiras de plantas com cores cloróticas, murchas nas horas mais quentes do dia e queda na produtividade (Dinardo \& Miranda, 2005; Ferraz \& Valle, 1997). Em algumas áreas, os nematoides poderão ser introduzidos pelas técnicas de cultivo empregadas.

O crescente aumento do trânsito de máquinas na lavoura durante as etapas de cultivo e colheita faz com que haja a maior possibilidade de transporte de patógenos e insetos-praga de uma região contaminada para outra região não contaminada. Os nematoides fitófagos podem provocar perdas na produção agrícola que, em média, variam de 20 a $40 \%$ em variedades suscetíveis (Campos, et al., 2006). Diante disso, este trabalho teve como objetivo identificar as populações de nematoides e suas características em uma área irrigada por pivô central do Instituto Federal Goiano - Campus Ceres, localizado na cidade de Ceres, Goiás, Brasil.

\section{Metodologia}

A área de estudo selecionada está localizada na área irrigada do Instituto Federal Goiano - Campus Ceres-GO. O relevo local é predominantemente plano a suavemente ondulado. O clima, conforme classificação de Köppen é o Aw (clima tropical de estações úmida e seca - Tropical Sazonal, de inverno seco), com medias anuais de $25{ }^{\circ} \mathrm{C}$ e $1.300 \mathrm{~mm}$ de precipitação.

As amostragens de solo georreferenciadas para determinação dos nematoides na área irrigada foram feitas no formato de grid regular e irregular, na profundidade de 0-20 cm. As amostras de solo (400 g) foram suspensas em 2 litros de água, posteriormente peneiradas em malha de 60 mesh e coletada em malha de 500 mesh pelo método da flutuação-sedimentação e peneiramento de Flegg \& Hopper (1970). A técnica da centrifugação foi adotada para clarificar as amostras (Jenkins, 1964). 
Conforme a técnica, os nematoides obtidos no peneiramento foram novamente suspensos em água e centrifugados (centrífuga marca FANEM modelo 204-NR) a 1800 RPM por 5 minutos.

Após a centrifugação, o "pellet" da amostra foi suspenso em solução de sacarose a 50\% e novamente centrifugado por 1 minuto a 1.800 RPM. Os sobrenadantes foram vertidos sobre peneira de 500 mesh para obter-se os nematoides em amostras clarificadas. Em seguida as amostras foram submetidas a uma temperatura de $60^{\circ} \mathrm{C}$ em banho-maria para causar a morte dos nematoides, sem que as estruturas do corpo não fossem danificadas. Logo após as amostras foram fixadas em solução de formalina $8 \%$ e reduzidas a um volume final de $10 \mathrm{~mL}$, onde os nematoides seriam identificados com auxílio de microscópio óptico. Baseando-se em características taxonômicas e parâmetros ecológicos, as comunidades de nematoides seriam analisadas em função dos seguintes parâmetros: Abundância, função trófica, padrão de decomposição da matéria orgânica, diversidade e distúrbio.

As análises granulométricas para quantificação dos componentes: areia, silte e argila; foram feitas seguindo a metodologia descrita no Manual de Métodos de Análises de Solo da Embrapa (1979). Nas análises químicas foram avaliados os seguintes atributos do solo: pH em água, $\mathrm{Al}, \mathrm{Ca}, \mathrm{Mg}, \mathrm{K}, \mathrm{P}, \mathrm{Na}$ e matéria orgânica (M.O.), seguindo a metodologia descrita pela Embrapa (1997).

Para analisar a variabilidade espacial dos nematoides na área da microbacia, utilizou-se da geoestatística, através da análise de semivariogramas, interpolação dos dados por krigagem e construção de mapas de isolinhas. Com os dados realiza-se amostragem dos mapas de isolinhas através de uma malha com distância predefinida pela equipe e avaliada a relação entre os mapas pela metodologia da correlação linear simples e diagrama de dispersão adaptada de Leite \& Landin (2003), que usaram análise de regressão. O software empregado é o ArcGis 9.3. Utiliza-se também da multivariada para representar o PCA dos índices relacionados com as análises nematológicas com auxílio do software Past.

\section{Resultados e Discussão}

A partir das amostragens de solo georreferenciadas, foram realizadas análises químicas, físicas e nematológicas. Para as análises das propriedades físicas e químicas, foi utilizada a metodologia proposta pela Embrapa onde os resultados mostraram uma boa qualidade do solo, com saturação de base acima de 50\% (Tabela 1).

$\mathrm{Na}$ análise granulométrica do solo, pode-se classificá-lo, segundo a Sociedade Brasileira de Ciência do Solo (Santos, et al., 2005), como de classe textural argilosa, para todos os pontos. As diferentes amostras de solo apresentaram relação silte/argila variando de 0,11 a 0,25 (Tabela 1). Os baixos valores de silte indicam que são solos bastantes intemperizados, já que a reduzida relação silte/argila, segundo Embrapa (1999), é um indicador do grau de intemperização. 


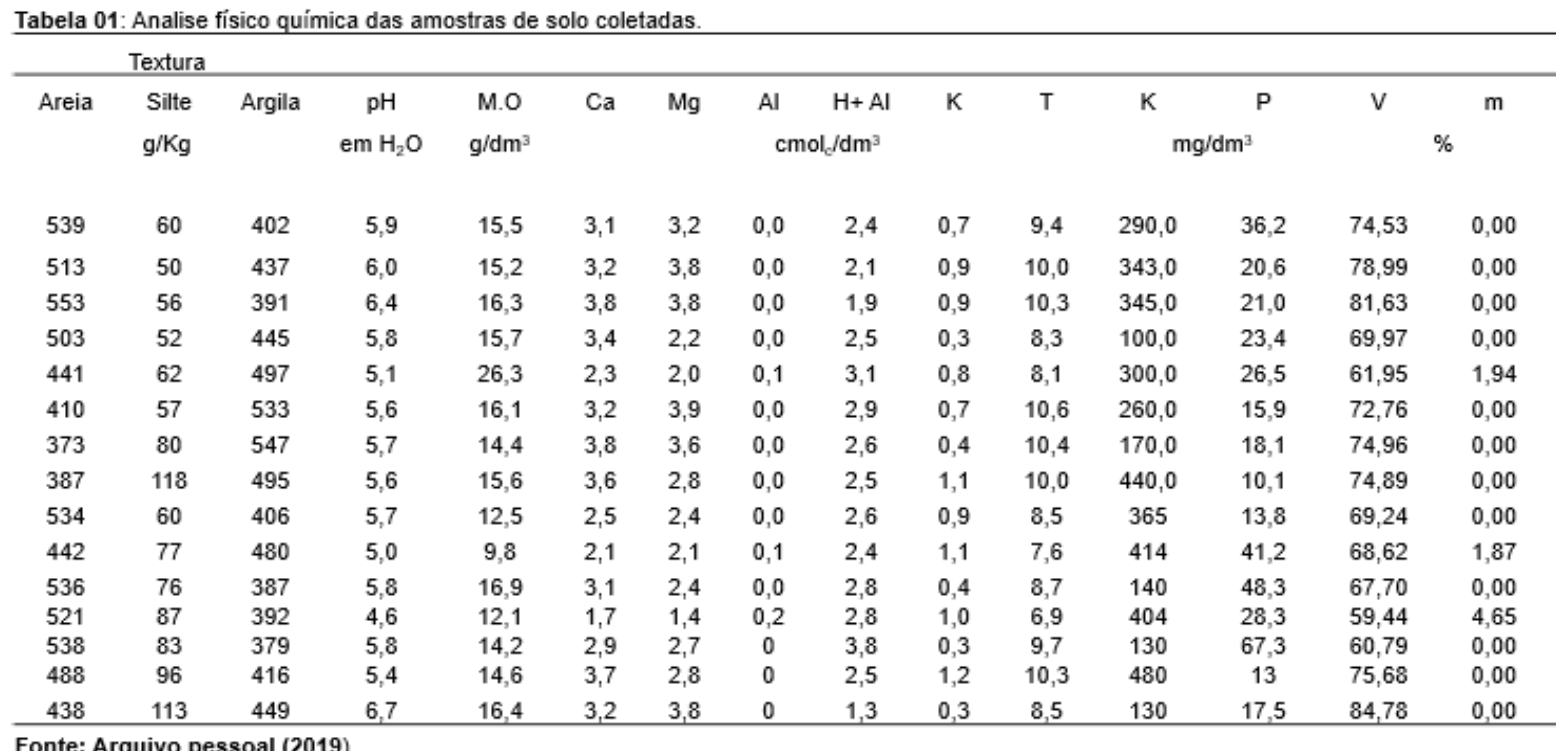

Depois de realizado o processo de extração, as amostras foram levadas ao microscópio ótico. Entretanto não foi observada a presença de nenhuma espécie de nematoide nas amostras. Segundo Dias (2019), os nematoides podem ser controlados pela rotação de cultivos com outras espécies não hospedeiras, uma adubação equilibrada com adubos verdes, controle eficiente de plantas daninhas, descompactação do solo, semeadura na época recomendada, inundação, pousio da área, solarização e adição/acumulo de M.O.

Á área irrigada do pivô central do Instituto Federal Goiano - Campus Ceres passa por diversos experimentos, com cultivares e espécies diferentes de plantas, ocorrendo assim, a diversificação e rotação na área. Nos últimos dois anos ocorreram os cultivos de: arroz (Oryza sativa L.) e milho (Zea mays L.) da família Poaceae; soja (Glycine max L.) e Feijão comum (Phaseolus vulgaris L.) pertencentes a família das Fabaceas, e espécies de gramíneas forrageiras como: Capim elefante (Pennisetum purpureum Schum), gênero brachiaria com diversas cultivares (Brizantha, Ruzizienses, etc.).

A adoção de plantas não hospedeiras como cobertura ou incorporação no solo, pode apresentar limitações caso estas não se estabeleçam rapidamente o que permitiria o crescimento de plantas daninhas. A escolha das espécies para rotação deve ser cuidadosa, pois, podem servir como hospedeiros alternativos para fitopatógenos. Além disso, a escolha e adoção das espécies deverá levar em conta a relação custo benefício, em função do lucro do produtor (Ritzinger \& Souza, 2000; Ritzinger \& McSorley, 1998).

Os resultados das análises químicas do solo demostraram uma quantidade de nutrientes com saturação de base dentro dos exigidos pela maioria das culturas. Ritzinger e Fancelli (2006) relatam que adubação potássica, fosfatada e nitrogenada no plantio da Musa sp. têm apresentado redução na densidade populacional, índice de galhas (IG) e aumento no desenvolvimento da planta. Entretanto a adubação com cálcio não apresentou efeito tão expressivo.

Triverdi e Barker (1986), relataram que os restos do sistema radicular infectado podem ser trazidos à superfície através da aração profunda. Portanto deve-se expor e revolver o solo periodicamente para dessecar as raízes diminuindo a sobrevivência dos fitonematoides na área. A maioria dos experimentos implantados na área irrigada do pivô da instituição utiliza o preparo convencional do solo, onde o revolvimento e preparo da área são realizados alguns meses antes da implantação dos experimentos, ficando assim a área em pousio. 
A eliminação das plantas espontâneas, possíveis hospedeiras alternativas, por no mínimo de seis meses, e o plantio e cultivo de plantas sadias são práticas que reduzem consideravelmente as populações de fitonematoides na área. Já a adoção da aração profunda exige cuidado, visto que pode ocasionar danos a estrutura e conservação do solo (McSorley \& Dickson, 1995). A combinação de práticas de pousio e sucessão de cultivos na área, utilizando diversas plantas como: cevada (Hordeum vulgaris), sesbania (Sesbania sp.), feijão (Phaseolus vulgaris L.), cravo (Tagetes sp.) e trigo (Triticum spp.) apresentaram-se como efetivas na diminuição das populações dos fitonematoides Rotylenchulus reniformis e Tylenchorhynchus brassicae (Linford \& Oliveira, 1940).

Já com relação às plantas antagônicas, a eficiência na sua adoção/uso pode ser influenciada por vários fatores relacionados ao solo como: umidade, fertilidade, matéria orgânica e com relação aos nematoides como as espécies e a densidade de indivíduos/população. O uso de plantas de cobertura altera vários fatores que influenciam no controle dos nematoides fitófagos como a relação carbono/nitrogênio, a massa seca e fresca, mudanças no pH, e o teor da M.O. (Triverdi \& Barker, 1986; McSorley,1998; Ritzinger \& Alves, 2001). Plantas armadilhas/iscas também podem ser utilizadas para o controle dos fitonematoides, estas plantas capturam e/ou causa a morte desses fitopatógenos (Altieri, 1987).

$\mathrm{O}$ alto teor de matéria orgânica encontrado nas amostras pode contribuir para que ocorra a diminuição dos nematoides na área, uma vez que a decomposição pode liberar compostos fenólicos que afetam os fitófagos, acarretando na diminuição da população desses fitopatógenos. Ritzinger et al. (1995) trabalhando com plantas antagônicas, Crotalaria paulinea Schrank e Crotalaria spectabilis Roth, observaram a redução dos nematoides. Ferraz e Valle (1997), por sua vez, relataram que tal manejo promove o desenvolvimento de microrganismos eficientes na redução dos fitoparasitas.

\section{Conclusão}

Não foi detectada a presença de nematoides fitopatogênicos na área irrigada do pivô central no Instituto Federal Goiano - Campus Ceres.

\section{Referências}

Agrios, G. N. (1997). Plant diseases caused by nematodes. (4a ed.), Plant Pathology San Diego. 565-597.

Altieri, M. A. (1987). Agroecology: the scientific bases of alternative agriculture. Westview press, 227.

Barker, K. R., Hussey, L. R., Krusberg, L.R ., Bird, G. W., Dunn, R. A., Ferris, H., Ferris, V. R., Freckman, D. W., Gabriel, C. J., Grewal, A. E., Mcguidwin, A .E., Riddle, D. L., Roberts, P. A. \& Schimitt, D. P. (1994). Plant and soil nematodes: societal impact and focus for the future. Journal of Nematology, Lakeland, 26, 127-137.

Bongers, T. (1990). The maturity Index an ecological measure of environmental disturbance based on nematode species composition. $O$ ecologia, 14-19.

Brasil, Conab. (2018). Acompanhamento da safra brasileira de cana-de-açúcar. https://www.conab.gov.br/info-agro/safras/cana.

Campos, A. P., Vale, D. W., Araújo, E. S., Corradi, M. M., Yamauti, M. S., Fernandes, O. A. \& Freitas. S. (2006). Manejo integrado de pragas. Jaboticabal: FUNEP, 59-80.

Curry, J. P. (1994). Grassland invertebrates. Ecology of soil fertility and effects on plant growth: Chapman \& Hall, 437.

Dinardo-Miranda, L. L. (2005). Manejo de fitonematoides em cana-de-açúcar. Jornal Cana: tecnologia agrícola, 5, $64-67$.

Embrapa, Centro Nacional de Pesquisa de Solos. (1979). Manual de métodos de análises de solo. Centro Nacional de Pesquisa de Solos, CNPS.

Embrapa, Centro Nacional de Pesquisa de Solos. (1997). Manual de métodos de análises de solo. Centro Nacional de Pesquisa de Solos, CNPS, 212.

Embrapa, Centro Nacional de Pesquisa de Solos. (1999). Sistema brasileiro de classificação de solos. Centro Nacional de Pesquisa de Solos, CNPS, 412.

Ferraz, S. \& Valle, L. A. C. (1997). Controle de fitonematóides por plantas antagônicas. Editora UFV, 73.

Flegg, J. J. \& Hooper, D. J. (1970). Extraction of free-living stages from soil. Ministry of Agriculture, Fisheries and Food, 148. 
Research, Society and Development, v. 10, n. 5, e54110515213, 2021

(CC BY 4.0) | ISSN 2525-3409 | DOI: http://dx.doi.org/10.33448/rsd-v10i5.15213

Freckmam D. W. \& Ettema, C. H. (1993). Assessing nematode communities in agroecosystems of varying human intervention, Agriculture. Ecosystems and Environment 45, 239-261.

Hussey, R. S. \& Williamson, V. M. (1998). Physiological and Molecular Aspects of nematode parasitism. Madison, Wisconsin: American Society of Agronomy, 87-108.

Jenkins, W. R. (1964). A rapid centrifugal-flotation technique for separating nematodes from soil. Plant Disease Report, 48, 692.

Leite, C. B. B. \& Landim, P. M. B. (2003). Relação entre mapas temáticos por meio da análise de regressão múltipla. Solos e Rochas, 95-203.

Linford, M. B., Yan, F. \& Oliveira, J. M. (1938). Reduction of soil populations of the root-knot nematode during decomposition of the organic matter. Soil Science, Baltimore, 45, 127-141.

Maggenti, A. (1981). General nematology. Springer-Verlag.

Margurran, A. E. (1988). Ecological diversity and its measurement. University Press, 179.

Mcsorley, R. \& Gallaher, R. N. (1995). Cultural practices improve crop tolerance to nematodes. Nematropica, Riverside, 25, 53-60.

Neher, D. A. (2001). Role of Nematode in soil health and their use as indicator. Journal of Nematology, 33(4), 161-168.

Poranziska, D. L. et al. (1998). Nematode communities as indicators of status and processes of a soil ecosystem influenced by agricultural management practices. Applied Soil Ecology, 13, 69-86.

Ritzinger, C. H. S. P. \& Souza, J. S. (2000). Situação dos problemas nematológicos na região norte do Brasil. Sociedade Brasileira de Nematologia: Instituto de Ciências Agrárias, Universidade Federal de Uberlândia, 82-86.

Ritzinger, C. H. S. P. \& Mcsorley, R. (1998). Effect of castor and velvetbean organic amendments on Meloidogyne arenaria in greenhouse experiments. Journal of Nematology, Lakeland, 30, 624-631.

Ritzinger, C. H. S. P. \& Alves, E. J. (2006). Nematóides. Cultivo de bananeira tipo Terra. Embrapa Mandioca e Fruticultura, Cruz das Almas, 117-122.

Santos, R. D., Lemos, R. C., Santos, H. G., Ker, J. C. \& Anjos, L. H. C. (2005). Manual de descrição e coleta de solo no campo. (5a ed.), SBCS/EMBRAPA/CNPS, 100.

Shannon, C. E. \& Weaver, W. (1949). The mathematical theory of communiation. The Univ.of Illinois Press, Urbana, IL.

Trivedi, P. C. \& Barker, K. R. (1986). Management of nematodes by cultural methods. Nematropica, Riverside, 16, 213-236.

Viglierchio, D. R. (1991). The World of Nematodes: a fascinating component of the animal kingdom. University of California: Davis, CA, 266.

Wansilewska, L. (1994). The effect of age of meadows on succession and diversity in soil nematode communities. Pedobiologia 38, 1-11.

Yeates, G, W., Bongers, T., Goede, Freckmam, D. W. \& Georgieva, S. S. (1993). Feeding habits in soil nematode families and genera-an outline for soil ecologists. Journal of nematology 25, 315-331. 